\title{
Outcome and risk of recurrence in a large cohort of idiopathic longitudinally extensive transverse myelitis without AQP4/MOG antibodies
}

Elisabeth Maillart ${ }^{1 *+}{ }^{\mathbb{D}}$, Françoise Durand-Dubief ${ }^{2+}{ }^{+}$, Céline Louapre ${ }^{1}$, Bertrand Audoin ${ }^{3}$, Bertrand Bourre ${ }^{4}$, Nathalie Derache ${ }^{5}$, Jonathan Ciron ${ }^{6}$, Nicolas Collongues ${ }^{7}$, Jérome de Sèze ${ }^{7}$, Mikael Cohen $^{8}$, Christine Lebrun-Frenay ${ }^{8}$, Nawel Hadhoum ${ }^{9}$, Hélène Zéphir ${ }^{9}$, Romain Deschamps ${ }^{10}$, Clarisse Carra-Dallière ${ }^{11}$, Pierre Labauge ${ }^{11}$, Philippe Kerschen ${ }^{12}$, Alexis Montcuquet ${ }^{13}$, Sandrine Wiertlewski ${ }^{14}$, David Laplaud ${ }^{14}$, Gwenaëlle Runavot ${ }^{15}$, Sandra Vukusic ${ }^{2}$, Caroline Papeix ${ }^{1}$, Romain Marignier ${ }^{2}$ and on behalf of the OFSEP, SFSEP, and NOMADMUS study groups

\begin{abstract}
Background: Longitudinally extensive transverse myelitis (LETM) is classically related to aquaporin (AQP4)-antibodies (Ab) neuromyelitis optica spectrum disorders (NMOSD) or more recently to myelin oligodendrocyte glycoprotein (MOG)-Ab associated disease. However, some patients remain negative for any diagnosis, despite a large work-up including AQP4-Ab and MOG-Ab. Data about natural history, disability outcome, and treatment are limited in this group of patients. We aimed to (1) describe clinical, biological, and radiological features of double seronegative LETM patients; (2) assess the clinical course and identify prognostic factors; and (3) assess the risk of recurrence, according to maintenance immunosuppressive therapy.
\end{abstract}

Methods: Retrospective evaluation of patients with a first episode of LETM, tested negative for AQP-Ab and MOG-Ab, from the French nationwide observatory study NOMADMUS.

Results: Fifty-three patients (median age 38 years (range 16-80)) with double seronegative LETM were included. Median nadir EDSS at onset was 6.0 (1-8.5), associated to a median EDSS at last follow-up of 4.0 (0-8). Recurrence was observed in $24.5 \%$ of patients in the 18 following months, with a median time to first relapse of 5.7 months. The risk of recurrence was lower in the group of patients treated early with an immunosuppressive drug $(2 / 22,9 \%)$, in comparison with untreated patients (10/31, 32\%).

Conclusions: A first episode of a double seronegative LETM is associated to a severe outcome and a high rate of relapse in the following 18 months, suggesting that an early immunosuppressive treatment may be beneficial in that condition.

Keywords: Longitudinally extensive transverse myelitis, Seronegative, Neuromyelitis optica, Outcome, Treatment

\footnotetext{
* Correspondence: elisabeth.maillart@aphp.fr

tElisabeth Maillart and Françoise Durand-Dubief contributed equally to this work.

'Department of Neurology; Centre de Référence des Maladies Inflammatoires

Rares du Cerveau et de la Moelle, AP-HP, Hôpital Pitié-Salpêtrière, Paris,

France

Full list of author information is available at the end of the article
}

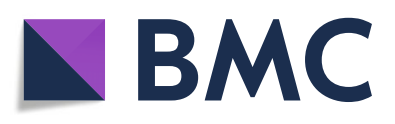

(- The Author(s). 2020 Open Access This article is licensed under a Creative Commons Attribution 4.0 International License, which permits use, sharing, adaptation, distribution and reproduction in any medium or format, as long as you give appropriate credit to the original author(s) and the source, provide a link to the Creative Commons licence, and indicate if changes were made. The images or other third party material in this article are included in the article's Creative Commons licence, unless indicated otherwise in a credit line to the material. If material is not included in the article's Creative Commons licence and your intended use is not permitted by statutory regulation or exceeds the permitted use, you will need to obtain permission directly from the copyright holder. To view a copy of this licence, visit http://creativecommons.org/licenses/by/4.0/. The Creative Commons Public Domain Dedication waiver (http://creativecommons.org/publicdomain/zero/1.0/) applies to the data made available in this article, unless otherwise stated in a credit line to the data. 


\section{Introduction}

Longitudinally extensive transverse myelitis (LETM) is defined as a myelitis that extends over at least three vertebral segments in length at spinal cord MRI and is frequently associated to a severe clinical presentation [1]. Although LETM is classically related to AQP4-antibodies $(\mathrm{Ab})$ neuromyelitis optica spectrum disorders (NMOSD) [2] or more recently to MOG-Ab associated disease [3], alternative diagnoses have to be excluded such as vascular, granulomatosis, paraneoplastic, metabolic, and infectious diseases [4]. However, despite a large work-up, some patients remain negative for any diagnosis, including AQP4-Ab and MOG-Ab associated disease. For these double seronegative LETM patients, current NMOSD criteria [5] are not fulfilled, and data about their natural history, disability outcome, and therapeutic recommendations are limited.

In this study, we aimed to (1) describe clinical, biological, and radiological features of double seronegative LETM patients; (2) assess the clinical course and identify prognostic factors; and (3) assess the risk of recurrence, according to maintenance immunosuppressive therapy.

\section{Methods}

\section{Participants}

Patients included in the study fulfilled the following criteria:

- First episode of myelitis, defined as progression to nadir symptoms as maximum duration between $4 \mathrm{~h}$ and 21 days following the onset of nadir, according the transverse myelitis Consortium Working Group [6]

- Associated with a T2 hyperintensity on spinal cord MRI extending over 3 vertebral segments

- Without previous neurological episode, especially optic neuritis

- Absence of both AQP4-Ab and MOG-Ab in serum detected either at onset of disease and during biological follow-up and tested using a cell-based assay in the French national reference laboratory [7]

- Age $\geq 16$ years at onset of disease

- Brain MRI at admission not suggestive of multiple sclerosis (MS)

- Negative comprehensive work-up

- Minimum clinical follow-up required for at least 1 year

The initial work-up [1] included a first clinical research of extra-neurological symptoms. It consisted in standard biological blood analysis hematological, and biochemical assays, autoimmune assays (antinuclear antibodies, antiphospholipid antibodies, ANCA, protein electrophoresis), viral (Herpesvirus group, hepatitis $\mathrm{B}$ and $\mathrm{C}$ ), bacteriological (syphilis, Lyme disease, tuberculosis) assessments, vitamin B12, full body CT scan, salivary gland biopsy, visual evoked potential, and ophthalmological examination. Brain and spinal cord
MRI were performed according to the French National Guidelines (OFSEP) [8]. MRI centralized evaluations were performed by neuroradiologist experts, to rule out MS or other identified inflammatory diagnosis.

\section{Data collection}

All requested information were retrospectively collected in a standardized evaluation form. Data collection was performed from January 2017 up to January 2019 and registered in the French nationwide database for NMOSD and associated neurologic disorders (NOMADMUS, a nested cohort of the Observatoire Français de la Sclérose en Plaques (OFSEP)). This form includes demographic data such as sex and age at disease onset; clinical data such as onset severity assessed by the Expanded Disability Status Scale (EDSS) score; biological data such as cerebrospinal fluid (CSF) pleïocytosis > 5 cells $/ \mathrm{mm}^{3}$, protein level $>0.5 \mathrm{~g} / \mathrm{L}$, and presence of oligoclonal bands (OCB); radiological features with localization and extension of the LETM and description of the brain MRI; acute and maintenance therapy; time to the first relapse; duration of follow-up; and EDSS and radiological evolution during the follow-up. Clinical and radiological outcomes were assessed by EDSS and brain and spinal cord MRI at 6, 12, 18, and 24 months, when available, and at the last visit. AQP4-Ab and MOG-Ab in serum were performed at onset of disease and during biological follow-up and tested using a cell-based assay in the French national reference laboratory.

Double entry of the same patient was excluded by a single code of pseudonymization for each patient in the national database and stringent data management.

\section{Standard protocol approvals, registrations, and patient consents}

All patients gave written informed consent to be included in NOMADMUS. Therefore, no additional consent or institutional review board approval was sought. All pseudonymized data were gathered in Pitié-Salpêtrière tertiary care center in Paris.

\section{Data availability}

This study was done within the framework of OFSEP. Because of national confidentiality requirements, only anonymized data, not pseudonymized data, can be shared. While anonymization techniques might result in impoverishment of data (Article 29 of Directive 95/46/ EC, Opinion 05/2014 on Anonymisation Techniques$0829 / 14 /$ EN WP 216), data used for this study were only pseudonymized. However, access to OFSEP data to conduct a scientific project is possible by following the OFSEP data access process (ofsep.org/en/data-access) and with respect to French law. 


\section{Statistical analyses}

Statistical analysis was performed using the $\mathrm{R}$ software (version 3.4.0). Clinical characteristics were compared between patients with or without a relapse in the first 18 months of follow-up using MannWhitney $U$ test or $\chi^{2}$ test for gender repartition and presence of OCB. The independent predictive value of demographic and clinical characteristics to determine the risk of relapse within the first 18 months (milestone reached by every patient) was assessed with stepwise multilinear regression by using the Akaike Information Criterion (stepAIC function in $\mathrm{R}$ statistical package).

\section{Results}

\section{Cohort description (Table 1)}

Fifty-three patients fulfilled inclusion criteria: 28 women/25 men. Mean age at onset was 38 years (range 16-80). Median EDSS at nadir was 6 (range 1-8.5). Interval between onset of symptoms and spinal cord MRI was 19 days (range 1-117). Spinal cord lesions were predominantly localized in the thoracic (81\%) and cervical (53\%) areas with a mean lesion length of 6.2 (range 3-16) vertebral segments. Lesions were described as transverse in 45 patients (85\%). No leptomeningeal enhancement was described.
Patients had normal brain MRI in $60 \%$ of cases, and not suggestive of MS in $40 \%$ of cases, with unspecific hyperintensities. No brain parenchymal or leptomeningeal gadolinium enhancement was identified.

Cerebrospinal fluid analyses at the acute phase revealed pleïocytosis $\left(>5\right.$ cells $/ \mathrm{mm}^{3}$ ) in $56 \%$ of patients with a median cell count of $12 / \mathrm{mm}^{3}$ (range 0-990). Forty-seven percent of patients had an elevated protein level with a mean at $0.70 \mathrm{~g} / \mathrm{L}$ (range $0.1-3.23 \mathrm{~g} /$ $\mathrm{L}$ ), and oligoclonal bands were present in the CSF of $30 \%$ of patients.

$\mathrm{AQP} 4-\mathrm{Ab}$ and MOG-Ab were negative at least twice, at the onset and during the patients' follow-up. For relapsing patients, AQP4-Ab and MOG-Ab were both reassessed at the acute phase and remain negative.

For all the patients included, the complete work-up was negative, thereby did not reveal any underlying condition, especially other autoimmune disease.

Patients were treated in a median delay of 10 days (range 2-360) after the first symptoms, in 52 patients (98 \%) by intravenous methylprednisolone (IVMP) (Table 2). A second line of treatment was performed in 24 patients (45\%), including plasmapheresis for $17 / 24$ patients (71\%), IVMP for $5 / 24$ patients $(21 \%)$, or intravenous immunoglobulins for

Table 1 Clinical, radiological, and CSF data at first episode of LETM

\begin{tabular}{|c|c|c|c|}
\hline Demographic data & $\begin{array}{l}\text { Whole } \\
\text { cohort }\end{array}$ & $\begin{array}{l}\text { Non-relapsing patients in the first } 18 \\
\text { months }\end{array}$ & $\begin{array}{l}\text { Relapsing patients in the first } 18 \\
\text { months }\end{array}$ \\
\hline$n$ & 53 & 41 & 12 \\
\hline Female, $n(\%)$ & $28(52.8)$ & $22(54 \%)$ & $6(50 \%)$ \\
\hline Age at onset, years median (range) & $38(16.5-80)$ & $38(16.5-80)$ & $43.2(26-65)$ \\
\hline Follow-up, years median (range) & $3.94(1.5-12)$ & $2.88(1.5-11.3)$ & $5.98(3.91-12)$ \\
\hline EDSS at nadir, median (range) & $6(1-8.5)$ & $6.5(1-8.5)$ & $5.25(1-8.5)$ \\
\hline \multicolumn{4}{|l|}{ Spinal cord MRI data ${ }^{a}$} \\
\hline . Cervical only & 7 & 6 & 1 \\
\hline . Thoracic only & 18 & 14 & 4 \\
\hline Lumbar only & 3 & 3 & 0 \\
\hline Cervical and thoracic & 14 & 10 & 4 \\
\hline Cervical, thoracic and lumbar & 7 & 6 & 1 \\
\hline Thoracic and lumbar & 4 & 2 & 2 \\
\hline . Cervical involvement, $n(\%)$ & $28(53 \%)$ & $22(54 \%)$ & $6(50 \%)$ \\
\hline Thoracic involvement, $n$ (\%) & $43(81 \%)$ & $32(78 \%)$ & $11(92 \%)$ \\
\hline . Lumbar involvement, $n$ (\%) & $14(26 \%)$ & $11(27 \%)$ & $3(25 \%)$ \\
\hline \multicolumn{4}{|l|}{ Laboratory data $^{\mathrm{b}}$} \\
\hline CSF OCB, $n=50, n(\%)$ & $15(30 \%)$ & $12 / 38(32 \%)$ & $3 / 12(25 \%)$ \\
\hline $\begin{array}{l}\text { CSF pleocytosis (> } 5 \text { cells } / \mathrm{mm}^{3} \text { ), } n=52, n \\
(\%)\end{array}$ & $28(54 \%)$ & $22 / 40(55 \%)$ & $6 / 12(50 \%)$ \\
\hline Proteinorachy (>0.5 g/L), $n=51, n(\%)$ & $24(47 \%)$ & 18/39 (46\%) & $6 / 12(50 \%)$ \\
\hline
\end{tabular}

LETM longitudinal extensive transverse myelitis, $y$ years, $m$ months, EDSS Expanded Disability Status Scale, CSF cerebrospinal fluid, OCB oligoclonal bands

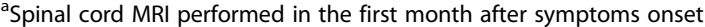

${ }^{b}$ Lumbar puncture performed during the first episode of LETM 
Table 2 LETM initial treatment

\begin{tabular}{ll}
\hline & This cohort \\
\hline $\begin{array}{l}\text { Delay of treatment after first symptoms (mean, days) } \\
\text { Infusions of methylprednisolone }\end{array}$ & 10 \\
$\begin{array}{l}\text { Second line of treatment }(n=24 / 53) \\
\text { Plasmapheresis }\end{array}$ & \\
Infusions of methylprednisolone & $17(71 \%)$ \\
IV immunoglobulins & $5(21 \%)$ \\
Third line of treatment ( $n=4 / 53)$ & $2(8 \%)$ \\
$\quad$ Infusions of methylprednisolone & $2(50 \%)$ \\
$\quad$ Plasmapheresis & $2(50 \%)$ \\
Relay by oral steroids ( $n=23 / 53)$ & \\
$\quad$ Duration (data for 15 patients) months & $7.2(0.2-12)$ \\
\hline LETM longitudinal extensive transverse myelitis, $I V$ intravenous &
\end{tabular}

$2 / 24$ patients $(8 \%)$. The median delay for this second line of treatment was 16 days (range 6-146). In addition, oral corticosteroids were prescribed for 23 patients (43\%), for a mean duration of treatment of 7.25 months (range $0.2-12$ months).

\section{Clinical and radiological follow-up (Fig. 1)}

Median EDSS improved from 6 to 5.25 at 6 months (range $0-8)(n=50), 4.75$ at 12 months (range $0-8)(n=$ $44)$, and 4.5 at 24 months (range $1-8)(n=40)$. At the last follow-up for a median duration of 3.94 years (1.5$12)$, median EDSS remained 4 (range $0-8)(n=53)$.

Twelve patients $(24.5 \%)$ experienced at least another relapse (myelitis or optic neuritis) in the first 18 months, with a median interval between the 2 clinical events of 171 days (5.7 months). Among them, 6 fulfilled the 2015 NMOSD criteria. When comparing patients with a relapse in the first 18 months $(n=12)$ to patients without relapse ( $n=41)$, we found no statistically significant difference for demographics and clinical variables (sex, age at onset, EDSS at nadir), biological (cellularity, presence of OCB), or radiological (location or number of vertebral segments) initial feature (Table 1). Because of the heterogeneity in the follow-up duration and the maintenance therapies, we focused on the relapses during the 18 first months (minimal duration of the follow-up in our cohort).

Concerning radiological evolution, no asymptomatic silent progression was reported. During MRI follow-up, all the LETM lesions decreased with spinal T2 high signal regression and disappearance of gadolinium enhancement the first 6 months, leading frequently to a spinal atrophy at the level of the LETM. No asymptomatic lesion appeared at brain MRI follow-up.

At the end of the follow-up, the final diagnosis was monofocal LETM in 35 patients, relapsing myelitis in 12 patients, and seronegative NMOSD according to 2015 criteria in 6 patients. No other disease such as sarcoidosis, neoplastic or paraneoplastic disorder, spinal cord infarction, or dural fistula was diagnosed at the end of the follow-up.

\section{Evaluation of maintenance therapies}

Among the 29 patients receiving maintenance therapies, five patients had several successive maintenance treatments ( 3 patients with 2 different treatments and 2 patients with 3 different treatments). The main used drugs were: mycophenolate mofetil (16) and rituximab (9). Other immunosuppressants included: azathioprine (5), cyclophosphamide (3), mitoxantrone (1), methotrexate (1), and infliximab (1).

Concerning the maintenance therapy, we defined 2 groups of patients: the first group received an early immunosuppressive treatment introduced in 6 months after the onset of the LETM management by neurologists. We identified 22 early immunosuppressive treated patients (Fig. 2). The mean delay of therapy onset was 2.8 months (range 0.5-6.3). Among them, 2 patients (9\%) had a relapse in the 18 following months (for both patients, 3 months after the LETM). The second group gathered the 31 untreated patients at the onset: among them, 10 patients (32\%) experienced a second relapse in the 18 following months.

The difference in terms of risk of recurrence in the 18 following months between the early treated group and the

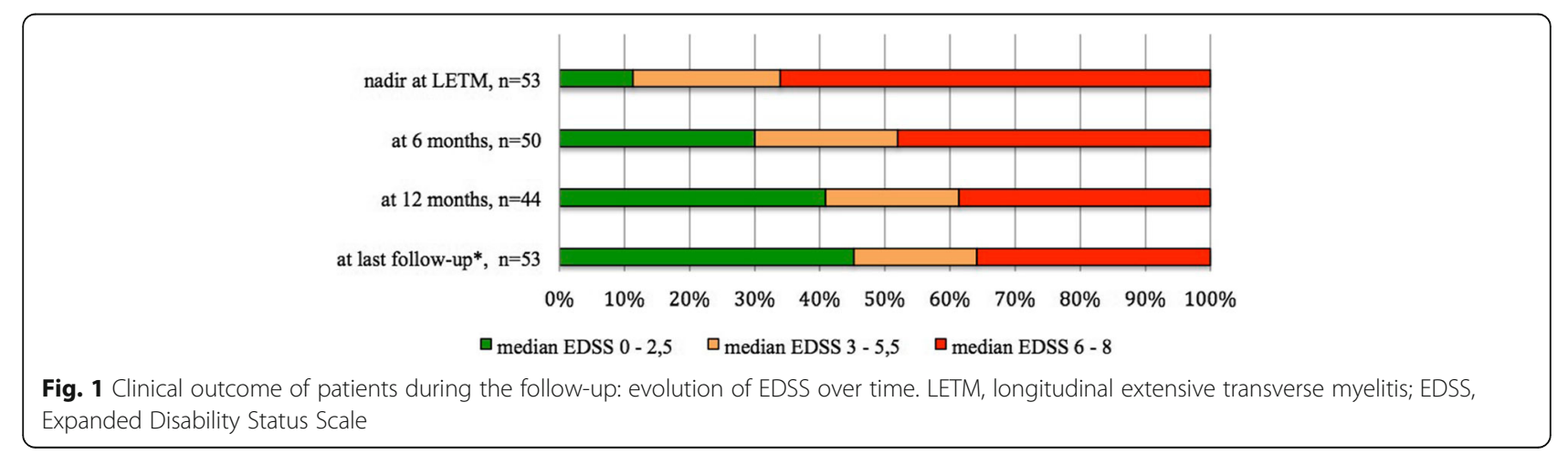




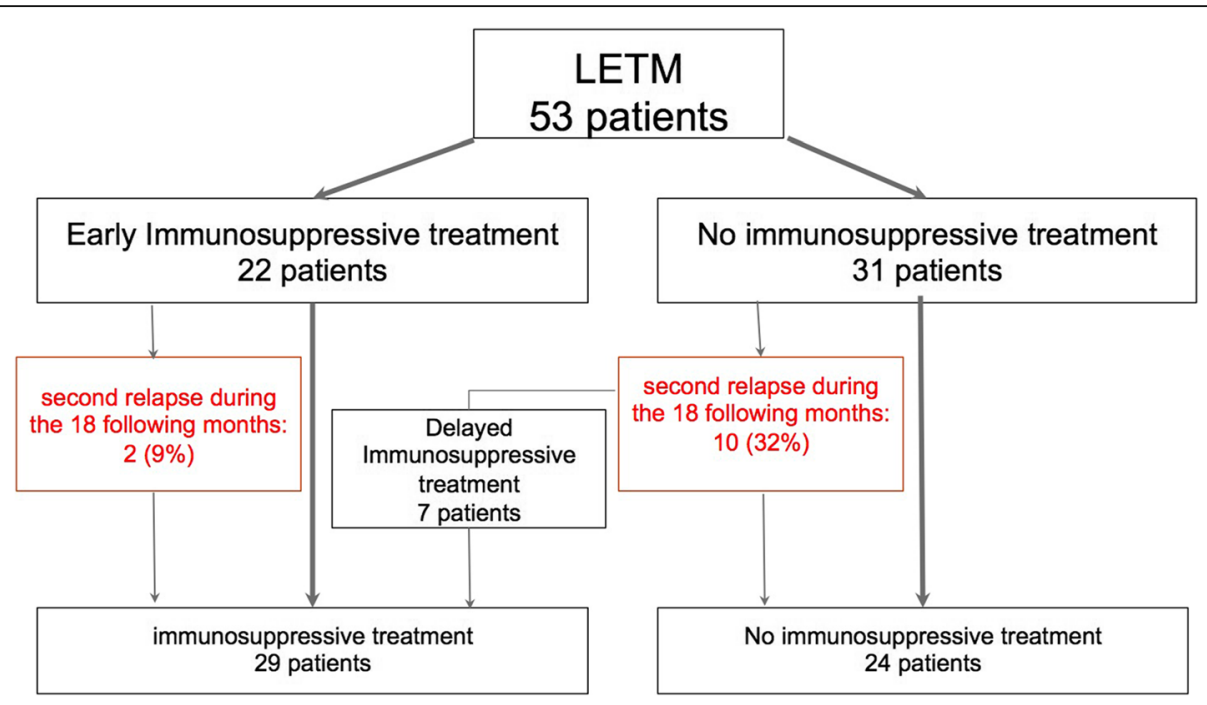

Fig. 2 Flow-chart of the therapeutic strategy. LETM, longitudinal extensive transverse myelitis

untreated group was not statistically significant ( $p=0.1$ by $\chi^{2}$ test). We identified 7 delayed immunosuppressive treated patients as they started their treatment after the second clinical event. None among them experienced a third relapse during the observatory period. We investigated the independent predictive value to determine the risk of at least one relapse during the first 18 months among the following dependent variables: sex, age at LETM, EDSS at the nadir, EDSS at M6, and start of early immunosuppressive treatment in the acute phase. The model enhanced that the unique predictive variable of the absence of a second clinical event during the first 18 months was the early treatment after the first episode of LETM $\left(p=0.048, \beta\right.$-estimate $=-0.23, R^{2}=0.07$; Odds Ratio 0.79 (95\% confidence interval 0.634-0.993)).

\section{Discussion}

This work provides the largest cohort to date of $53 \mathrm{pa}-$ tients with AQP4-Ab and MOG-Ab negative LETM, from the French, multicentric, nationwide observatory NOMADMUS, a nested cohort of the OFSEP. All these patients underwent a large standardized and comprehensive work-up to rule out conventional differential diagnosis such as vascular (i.e., dural fistula), granulomatosis, paraneoplastic, metabolic, and infectious diseases. Clinical and radiological data at onset and outcome have been accurately collected with evaluation of treatment effect. In this cohort, the majority of patients experienced a severe LETM (median nadir EDSS of 6.0). The outcome was poor with very partial recovery for most of the patients (median EDSS at 4), with a median followup of nearly 4 years. Besides, recurrence was observed in $24.5 \%$ of patients, mainly in the first year. The risk of recurrence trended to be higher in the group of patients with delayed immunosuppressive treatment (32\%) than in the group of patients with early immunosuppressive treatment (9\%).

Before starting a longer term immunosuppression, neurologists must be very stringent, trying to exclude difficult differential diagnosis [9] such as neurosarcoidosis, spinal cord infarction [10], or dural fistula. Neurologists need to be aware of evocative MRI patterns of alternative diseases: leptomeningeal enhancement or trident pattern of enhancement in neurosarcoidosis, compressive aspect or mass lesion in a spinal tumor, patchy anterior horn T2 hyperintensities in a spinal cord infarction, and serpiginous vessels in a spinal dural arteriovenous fistula, as proposed in series of idiopathic transverse myelitis [9]. In this study, to avoid misdiagnosis, inclusion criteria were stringent, and MRI was performed following the OFSEP protocol, centrally analyzed by neuroradiological experts in the field, which is a guarantee of quality. Beyond MRI pattern, the question of the exhaustive work-up is crucial is AQP4/MOG seronegative LETM. As the reported cases are retrospective and collected data are multicentric, some explorations were realized case by case. For example, PET scan is known to be more sensitive that CT scan to detect systemic sarcoidosis, for the staging and identification of occult sites and sites suitable for biopsy [11]. But for historical and availability issues, PET scan was not performed in every patient. Nowadays, realization of PET scan needs to be discussed in the work-up of an unexplained LETM. Moreover, infectious etiologies need to be rule out with comprehensive CSF analysis, including rare etiologies such as enterovirus D68.

Available data on LETM with negative AQP4-Ab and MOG-Ab are scarce (Table 3). In a Korean cohort [12] 
Table 3 Comparison of different cohorts of seronegative LETM

\begin{tabular}{|c|c|c|c|c|c|c|c|c|c|c|}
\hline Publication & $\begin{array}{l}\text { Patients } \\
\text { number }\end{array}$ & $\begin{array}{l}\text { Age at LETM } \\
\text { onset (range) } \\
\text { years }\end{array}$ & $\begin{array}{l}\text { Sex } \\
\text { ratio }\end{array}$ & $\begin{array}{l}\mathrm{AQP4} \\
\mathrm{Ab}\end{array}$ & $\begin{array}{l}\mathrm{MOG} \\
\mathrm{Ab}\end{array}$ & $\begin{array}{l}\text { Median EDSS } \\
\text { at nadir } \\
\text { (range) }\end{array}$ & $\begin{array}{l}\text { Chronic } \\
\text { treatment }\end{array}$ & $\begin{array}{l}\text { At least one } \\
\text { relapse after }\end{array}$ & $\begin{array}{l}\text { Follow-up duration, } \\
\text { (range) }\end{array}$ & $\begin{array}{l}\text { Median EDSS at } \\
\text { follow-up } \\
\text { (range) }\end{array}$ \\
\hline $\begin{array}{l}\text { Sepulveda } \\
\text { et al. [13] }\end{array}$ & 23 & $\begin{array}{l}\text { Median } 44.5 \\
(20-77)\end{array}$ & $\begin{array}{l}16 \mathrm{~F} \\
7 \mathrm{M}\end{array}$ & 2 & NA & $7(3-9)$ & $\begin{array}{l}12 / 23 \\
52 \%\end{array}$ & $6 / 20,30 \%$ & $\begin{array}{l}\text { Median } 32 \text { months } \\
(6-54)\end{array}$ & $2.5(0-8)$ \\
\hline $\begin{array}{l}\text { Kitley } \\
\text { et al. [15] }\end{array}$ & $\begin{array}{l}32 \\
\text { including } \\
\text { MS, ADEM }\end{array}$ & $\begin{array}{l}\text { Mean } 37.74( \pm \\
16.07)\end{array}$ & $\begin{array}{l}14 \mathrm{~F} \\
18 \\
\mathrm{M}\end{array}$ & 0 & 6 & $8(3-8)$ & NA & $31 \%$ & $\begin{array}{l}\text { Median } 25 \text { months } \\
(1.9-169.4)\end{array}$ & $\begin{array}{l}\text { EDSS at } \\
\text { recovery } 3(3-8)\end{array}$ \\
\hline $\begin{array}{l}\text { Huyn et al. } \\
{[12]}\end{array}$ & 42 & $\begin{array}{l}\text { Mean } 43.1( \pm \\
9.8)\end{array}$ & $\begin{array}{l}9 \mathrm{~F} \\
33 \\
M\end{array}$ & 0 & 0 & $3(3-8.5)$ & NA & $30,71 \%$ & Mean $5.4 \pm 2.6$ years & $2.5(1-6)$ \\
\hline $\begin{array}{l}\text { Cobo- } \\
\text { Calvo } \\
\text { et al. [14] }\end{array}$ & $\begin{array}{l}56 \\
\text { including } \\
\text { MS }\end{array}$ & $\begin{array}{l}\text { Median } \\
39.9(32.3-58.1)\end{array}$ & $\begin{array}{l}30 \mathrm{~F} \\
16 \\
\mathrm{M}\end{array}$ & 0 & 13 & $5.0(3.5-7.8)$ & $\begin{array}{l}19 / 56 \\
33.9 \%\end{array}$ & $16,28.6 \%$ & $\begin{array}{l}\text { Median } 42.2 \text { months } \\
(25-79.5)\end{array}$ & $2.5(1.5-4.8)$ \\
\hline $\begin{array}{l}\text { This } \\
\text { cohort }\end{array}$ & 53 & $\begin{array}{l}\text { Median } 38 \text { (16- } \\
\text { 80) }\end{array}$ & $\begin{array}{l}28 \mathrm{~F} \\
25 \\
M\end{array}$ & 0 & 0 & $6(1-8.5)$ & $\begin{array}{l}29 / 53 \\
55 \%\end{array}$ & $\begin{array}{l}12 / 53 \\
24.5 \%\end{array}$ & $\begin{array}{l}\text { Median } 3.94 \text { years } \\
(1.5-12) \text { mean } 4.47 \\
\text { years }\end{array}$ & $4(0-8)$ \\
\hline
\end{tabular}

$A b$ antibody, EDSS Expanded Disability Status Scale, $F$ female, $M$ male, $M S$ multiple sclerosis, ADEM acute disseminated encephalomyelitis

including 42 patients with double seronegative LETM in comparison to our findings, the outcome was better (median EDSS score at 2.5), but the attack was also initially less severe at nadir (median nadir EDSS at 3.0). The rate of relapse was higher (71\%) with a median time to the first relapse of 11.5 months (range 2-72). However, $57 \%$ of patients were untreated at the final follow-up, versus $45 \%$ in our study. Two Spanish cohorts $[13,14]$ found similar results, with high EDSS at nadir, and a slightly higher relapse rate $(28.6-30 \%)$ but with better outcome (median EDSS 2.5 at the end of follow-up). However, inclusion criteria differed, with MOG-Ab status unknown on one hand [13], and inclusion of patients with LETM related to MS on the other hand [14]. An English cohort [15] including patients with MS or ADEM found similar high EDSS at nadir associated to a better recovery (EDSS at 3 ). The relapse rate was increased to $31 \%$, maybe because of inclusion of MS patients. Finally, a monocenter retrospective study including 192 patients with transverse myelitis (and not necessary LETM) found a rate of recurrence around 57\% [16]. Multiple independent risk factors for recurrence were found, such as African American race, female sex, and LETM at onset, maybe partly driven by a greater likelihood of developing NMOSD. Overall, we need to keep in mind that the effect and the early initiation of the attack treatment are important factors when assessing clinical recovery, as it has been previously demonstrated for IVMP or PLEX $[17,18]$.

Beyond the clinical phenotype of LETM, the severity of double seronegative NMOSD has been previously pointed. In a cohort of 181 patients fulfilling the 2006 NMO criteria or NMO limited forms with AQP4-Ab [19], patients with AQP4-Ab or double seronegative had significant poorer outcome than patients with 2006 NMO criteria and MOG-Ab. Even if some studies report functional and microstructural damages in MOG-Ab optic neuritis [20,21], visual recovery measured by visual acuity seems poorer in double seronegative and AQP4-Ab patients with optic neuritis [22]. Concerning radiological features, LETM lesions in patients fulfilling 2006 NMO criteria differentiated with fragmentation and atrophy [23]. In the Spanish cohort of double seronegative LETM, lesions decreased, disappeared, or remain stable: atrophy was reported in $14 \%$ of patients. On the opposite of MOG-associated disease, similar clinical evolution in patients with seronegative NMOSD and AQP4-Ab suggest a common physiopathology with acute axonal injury, poor recovery, and spinal atrophy.

Indication of an immunosuppressive therapy after a double seronegative LETM has not been studied in a randomized prospective trial because of the scarcity of this disorder. In this cohort, the difference in terms of risk of recurrence relapse in the first 18 months between the patients treated after the LETM or untreated patients was not statistically significant, probably due to the small number of patients in our cohort. However, the only predictive variable of the absence of a second clinical event during the first 18 months was the early immunosuppressive treatment after LETM suggesting that early treatment might decrease the risk of recurrence. Mycophenolate mofetil and rituximab have been preferentially used because of probable efficacy in NMOSD, especially with AQP4-Ab [24-26]. More data are needed, in the light of the recently described lower efficacy of anti-CD20 in the MOG-antibody associated diseases [27]. Finally, as immunosuppressive treatments take time to be effective, an association with oral steroid should be prescribed during the first 6 months to prevent early relapses and to avoid changing too early the maintenance therapy [24]. 


\section{Limitations}

First, some limitations of this study are inherent due to its retrospective design. Then, even we used strict inclusion criteria, this cohort is possibly heterogeneous, which is in part due to multicenter effect. Despite this heterogeneity, the strict inclusion criteria, the common negative initial work-up, the expertise of the different centers participating to this work, and the long clinical and MRI follow-up allow speculating that our patients share common features.

Second, even if a clinical neuro-ophthalmological evaluation and visual evoked potentials (VEP) were realized, an exhaustive visual system assessment was not systemically performed, especially with optical coherence tomography (OCT). Indeed, alteration of VEP and/or OCT is not considered in the 2015 NMOSD criteria. However, in some NMOSD patients without optic neuritis history, infraclinical foveal thickness in OCT [28] or slight increasing of latency of P100 in VEP [29] was reported. Association of VEP and OCT could be interesting prognostic biomarkers in double seronegative LETM.

Third, management of maintenance therapy varied according to the centers and the local practices, in particular with the increasing use of rituximab after LETM in suspected NMOSD during these last 10 years.

Fourth, GFAP antibodies were not tested retrospectively in the CSF of the patients in our cohort. This recent entity is defined as a distinct autoimmune astrocytopathy, responsible for a corticosteroid-responsive meningo-encephalomyelitis. Nevertheless, in the recent publication of 13 patients with LETM associated to GFAP-antibodies [30], all have extraspinal symptoms simultaneously or preceding myelitis onset, on the contrary to our patients. Such as recent identification of GFAP antibodies, other antibodies could be identified in the future and help to break down this heterogeneous entity of seronegative LETM.

\section{Conclusion}

In our cohort, the outcome of the 53 patients with double seronegative longitudinal extensive transverse myelitis was frequently severe, and the rate of relapse in the following 18 months was high. After a comprehensive work-up and an attentive analysis of both brain and spinal cord MRI to rule out any possible alternative diagnoses, an early immunosuppressive treatment may be beneficial in that condition. Better knowledge of physiopathology and identification of risk factors for recurrence are required, yielding to prospective randomized controlled trials.

\section{Abbreviations \\ LETM: Longitudinal extensive transverse myelitis; EDSS: Expanded Disability Status Scale; CSF: Cerebrospinal fluid; OCB: Oligoclonal bands; Ab: Antibody;} MS: Multiple sclerosis; ADEM: Acute disseminated encephalomyelitis

\section{Authors' contributions}

EM, FDD, CP, and RM conceived, designed, and wrote the manuscript of the study. $\mathrm{CL}$ performed the statistical analysis. EM set up the database collecting all the data. All authors listed have revised the manuscript for intellectual contribution to the work. All authors read and approved the final draft for publication.

\section{Funding}

The present study is supported by a grant from ARSEP foundation and a grant provided by the French State and handled by the "Agence Nationale de la Recherche", within the framework of the "Investments for the Future" programme, under the reference ANR- 551 10-COHO-002 Observatoire Français de la Sclérose en Plaques (OFSEP).

\section{Availability of data and materials}

This study was done within the framework of OFSEP. Because of national confidentiality requirements, only anonymized data, not pseudonymized data, can be shared. While anonymization techniques might result in the impoverishment of data (Article 29 of Directive 95/46/EC, Opinion 05/2014 on Anonymisation Techniques-0829/14/EN WP 216), data used for this study were only pseudonymized.

\section{Ethics approval and consent to participate}

The study was approved by the ethics committee of the University Hospital of Lyon, France. All patients gave their informed consent to participate in the study.

\section{Consent for publication}

Not applicable

\section{Competing interests}

The authors declare that they have no competing interests. No disclosure relevant to the manuscript.

\section{Author details}

${ }^{1}$ Department of Neurology; Centre de Référence des Maladies Inflammatoires Rares du Cerveau et de la Moelle, AP-HP, Hôpital Pitié-Salpêtrière, Paris, France. ${ }^{2}$ Service de neurologie, sclérose en plaques, pathologies de la myéline et neuro-inflammation, and Centre de Référence des Maladies Inflammatoires Rares du Cerveau et de la Moelle, Hôpital Neurologique Pierre Wertheimer, Hospices Civils de Lyon, 69677 Lyon/Bron, France. ${ }^{3}$ APHM, Hôpital de la Timone, Pôle de Neurosciences Cliniques, Service de Neurologie, Marseille, France. ${ }^{4}$ Department of Neurology, University Hospital of Rouen, Rouen, France. ${ }^{5}$ Department of Neurology, University Hospital of Caen, Caen, France. ${ }^{6}$ Department of Neurology, University Hospital of Toulouse, Toulouse, France. ${ }^{7}$ Department of Neurology, University Hospital of Strasbourg, Strasbourg, France. ${ }^{8}$ Centre de Ressources et Compétence Sclerose en plaques (CRCSEP); Unité de Recherche Clinique Côte d'azur (UR2CA), CHU Pasteur 2, Nice, France. ${ }^{9}$ Department of Neurology, University Hospital of Lille, Lille, France. ${ }^{10}$ Department of Neurology, Fondation Ophtalmologique Adolphe de Rothschild, 25-29, rue Manin, 75940 Paris cedex 19, France. ${ }^{11}$ Department of Neurology, University Hospital of Montpellier, Montpellier, France. ${ }^{12}$ Department of Neurology, University Hospital of Luxembourg, Luxembourg, Luxembourg. ${ }^{13}$ Department of Neurology, University Hospital of Limoges, Limoges, France. ${ }^{14}$ Department of Neurology, University Hospital of Nantes, Nantes, France. ${ }^{15}$ Department of Neurology, University Hospital of Saint-Pierre, Saint-Pierre, La Réunion, France.

Received: 10 January 2020 Accepted: 16 March 2020

Published online: 23 April 2020

\section{References}

1. Collongues N, Papeix C, Zephir H, Audoin B, Cotton F, Durand-Dubief F, et al. Nosology and etiologies of acute longitudinally extensive transverse myelitis. Revue Neurol. 2014;170(1):6-12.

2. Weinshenker BG, Wingerchuk DM, Vukusic S, Linbo L, Pittock SJ, Lucchinetti CF, et al. Neuromyelitis optica lgG predicts relapse after longitudinally extensive transverse myelitis. Ann Neurol. 2006;59(3):566-9.

3. Cobo-Calvo A, Ruiz A, Maillart E, Audoin B, Zephir H, Bourre B, et al. Clinical spectrum and prognostic value of CNS MOG autoimmunity in adults: the MOGADOR study. Neurology. 2018;90(21):e1858-e69.

4. Tobin WO, Weinshenker BG, Lucchinetti CF. Longitudinally extensive transverse myelitis. Curr Opin Neurol. 2014;27(3):279-89. 
5. Wingerchuk DM, Banwell B, Bennett $J$, Cabre P, Carroll W, Chitnis T, et al. International consensus diagnostic criteria for neuromyelitis optica spectrum disorders. Neurology. 2015;85(2):177-89.

6. Transverse Myelitis Consortium Working G. Proposed diagnostic criteria and nosology of acute transverse myelitis. Neurology. 2002;59(4):499-505.

7. Marignier R, Bernard-Valnet R, Giraudon P, Collongues N, Papeix C, Zephir H, et al. Aquaporin-4 antibody-negative neuromyelitis optica: distinct assay sensitivity-dependent entity. Neurology. 2013;80(24):2194-200.

8. Cotton F, Kremer S, Hannoun S, Vukusic S, Dousset V. Imaging Working Group of the Observatoire Francais de la Sclerose en P. OFSEP, a nationwide cohort of people with multiple sclerosis: consensus minimal MRI protocol. J Neuroradiol. 2015;42(3):133-40.

9. Zalewski NL, Flanagan EP, Keegan BM. Evaluation of idiopathic transverse myelitis revealing specific myelopathy diagnoses. Neurology. 2018;90(2): e96-e102.

10. Zalewski NL, Rabinstein AA, Krecke KN, Brown RD Jr, Wijdicks EFM, Weinshenker BG, et al. Characteristics of spontaneous spinal cord infarction and proposed diagnostic criteria. JAMA Neurol. 2019;76(1):56-63.

11. Treglia G, Annunziata S, Sobic-Saranovic D, Bertagna F, Caldarella C, Giovanella L. The role of 18F-FDG-PET and PET/CT in patients with sarcoidosis: an updated evidence-based review. Acad Radiol. 2014;21(5): 675-84

12. Hyun JW, Kim SH, Huh SY, Kim W, Yun J, Joung A, et al. Idiopathic aquaporin-4 antibody negative longitudinally extensive transverse myelitis. Multiple Sclerosis. 2015;21(6):710-7.

13. Sepulveda M, Blanco Y, Rovira A, Rio J, Mendibe M, Llufriu S, et al. Analysis of prognostic factors associated with longitudinally extensive transverse myelitis. Multiple Sclerosis. 2013;19(6):742-8.

14. Cobo-Calvo A, Sepulveda M, Bernard-Valnet R, Ruiz A, Brassat D, MartinezYelamos $\mathrm{S}$, et al. Antibodies to myelin oligodendrocyte glycoprotein in aquaporin 4 antibody seronegative longitudinally extensive transverse myelitis: clinical and prognostic implications. Multiple Sclerosis. 2016;22(3):312-9.

15. Kitley J, Leite MI, Kuker W, Quaghebeur G, George J, Waters P, et al. Longitudinally extensive transverse myelitis with and without aquaporin 4 antibodies. JAMA Neurol. 2013;70(11):1375-81.

16. Kimbrough DJ, Mealy MA, Simpson A, Levy M. Predictors of recurrence following an initial episode of transverse myelitis. Neurol Neuroimmunol Neuroinflamm. 2014;1(1):e4.

17. Kleiter I, Gahlen A, Borisow N, Fischer K, Wernecke KD, Hellwig K, et al. Apheresis therapies for NMOSD attacks: a retrospective study of 207 therapeutic interventions. Neurol Neuroimmunol Neuroinflamm. 2018;5(6):e504.

18. Kleiter I, Gahlen A, Borisow N, Fischer K, Wernecke KD, Wegner B, et al. Neuromyelitis optica: evaluation of 871 attacks and 1,153 treatment courses. Ann Neurol. 2016;79(2):206-16.

19. Sepulveda M, Armangue T, Sola-Valls N, Arrambide G, Meca-Lallana JE, Oreja-Guevara C, et al. Neuromyelitis optica spectrum disorders: comparison according to the phenotype and serostatus. Neurol Neuroimmunol Neuroinflamm. 2016;3(3):e225.

20. Pache F, Zimmermann H, Mikolajczak J, Schumacher S, Lacheta A, Oertel FC, et al. MOG-lgG in NMO and related disorders: a multicenter study of 50 patients. Part 4: afferent visual system damage after optic neuritis in MOGlgG-seropositive versus AQP4-lgG-seropositive patients. J Neuroinflammation. 2016;13(1):282

21. Jelcic I, Hanson JVM, Lukas S, Weber KP, Landau K, Pless M, et al. Unfavorable structural and functional outcomes in myelin oligodendrocyte glycoprotein antibody-associated optic neuritis. J Neuroophthalmol. 2019;39(1):3-7.

22. Deschamps R, Gueguen A, Lecler A, Lecouturier K, Lamirel C, Bensa C, et al. Acute idiopathic optic neuritis: not always benign. Eur J Neurol. 2018;25(11):1378-83.

23. Asgari N, Skejoe HP, Lillevang ST, Steenstrup T, Stenager E, Kyvik KO. Modifications of longitudinally extensive transverse myelitis and brainstem lesions in the course of neuromyelitis optica (NMO): a population-based, descriptive study. BMC Neurol. 2013;13:33.

24. Montcuquet A, Collongues N, Papeix C, Zephir H, Audoin B, Laplaud D, et al. Effectiveness of mycophenolate mofetil as first-line therapy in AQP4$\operatorname{lgG}, M O G-\lg G$, and seronegative neuromyelitis optica spectrum disorders. Multiple Sclerosis. 2017;23(10):1377-84.

25. Mealy MA, Wingerchuk DM, Palace J, Greenberg BM, Levy M. Comparison of relapse and treatment failure rates among patients with neuromyelitis optica: multicenter study of treatment efficacy. JAMA Neurol. 2014;71(3):324-30.
26. Collongues $\mathrm{N}$, de Seze J. An update on the evidence for the efficacy and safety of rituximab in the management of neuromyelitis optica. Ther Adv Neurol Disord. 2016;9(3):180-8.

27. Whittam. Treatment of MOG-lgG-associated demyelination with Rituximab: a multinational study of 98 patients. Neurology; 23 April 20182018.

28. Oertel FC, Kuchling J, Zimmermann H, Chien C, Schmidt F, Knier B, et al. Microstructural visual system changes in AQP4-antibody-seropositive NMOSD. Neurol Neuroimmunol Neuroinflamm. 2017;4(3):e334.

29. Vabanesi M, Pisa M, Guerrieri S, Moiola L, Radaelli M, Medaglini S, et al. In vivo structural and functional assessment of optic nerve damage in neuromyelitis optica spectrum disorders and multiple sclerosis. Sci Rep. 2019;9(1):10371.

30. Sechi E, Morris PP, McKeon A, Pittock SJ, Hinson SR, Weinshenker BG, et al. Glial fibrillary acidic protein lgG related myelitis: characterisation and comparison with aquaporin-4-lgG myelitis. J Neurol Neurosurg Psychiatr. 2019;90(4):488-90.

\section{Publisher's Note}

Springer Nature remains neutral with regard to jurisdictional claims in published maps and institutional affiliations.
Ready to submit your research? Choose BMC and benefit from:

- fast, convenient online submission

- thorough peer review by experienced researchers in your field

- rapid publication on acceptance

- support for research data, including large and complex data types

- gold Open Access which fosters wider collaboration and increased citations

- maximum visibility for your research: over $100 \mathrm{M}$ website views per year

At BMC, research is always in progress.

Learn more biomedcentral.com/submissions 